Article

\title{
Nutritional, Antioxidant and Quality Acceptability of Smoothies Supplemented with Moringa oleifera Leaves
}

\author{
Taiwo Ayodele Aderinola $\mathbb{D}$ \\ Department of Food Science and Technology, The Federal University of Technology, Akure PMB 704, Nigeria; \\ taaderinola@futa.edu.ng; Tel.: +23-470-3656-9677
}

Received: 15 November 2018; Accepted: 10 December 2018; Published: 16 December 2018

\begin{abstract}
This study evaluated the impact of the level of supplementation (1.5, 3.0 and 4.5\%) of Moringa oleifera leaves on the nutritional (proximate, mineral and vitamin contents) and antioxidant capacities of smoothies made from a blend of pineapple, banana and apple. The results obtained were moisture (49.24-78.62\%), total ash (1.01-9.71), crude fiber (5.14-9.39\%), crude fat (0.72-1.86\%), crude protein (5.47-19.37\%) and carbohydrate (3.65-16.99\%). Calcium (12.03-15.53) and potassium (17.22-25.38) were the predominant mineral elements when compared to magnesium $(1.51-3.05) \mathrm{mg} / \mathrm{L}$. The vitamin contents were in the ranges $2.5-10.8$ and $0.15-0.93 \mathrm{mg} / \mathrm{L}$ for vitamins $\mathrm{C}$ and E, respectively. Total phenolic and flavonoid contents were in the ranges $4.68-6.18 \mathrm{mg} / \mathrm{mL}$ and $0.01-0.14 \mathrm{mg} / \mathrm{mL}$, respectively. The radical scavenging abilities (DPPH) of the samples ranged between $16.05 \%$ and $88.77 \%$, while the ferric reducing antioxidant power (FRAP) ranged between 0.38 and $7.36 \mathrm{mg} / \mathrm{mL}$. The brix values showed high sugar contents (15-18\%) while the $\mathrm{pH}$ results showed that the sample was almost neutral at a range between 6.3 and 6.5. The overall quality (sensory) acceptability of the different quality parameters evaluated indicated that the control sample was more preferred. While supplementation with $M$. oleifera leaves significantly affected the sensory parameters, its addition nevertheless offers a potential avenue to obtain additional nutrients besides its improved antioxidative properties.
\end{abstract}

Keywords: chemical composition; smoothies; fruit blends; antioxidant properties; Moringa oleifera leaf; sensory evaluation

\section{Introduction}

While the awareness for consumption of fresh fruit or fresh fruit juices is globally acknowledged due to its health promoting abilities [1,2], an often over-looked aspect is its somewhat restricted nutritional composition. In addition, markets for smoothie-like products are already established in some developed countries, generating over 2 billion USD and 141 million pounds in the USA and UK, respectively [3]. Fruits are generally rich sources of micronutrient-minerals and vitamins [1]. They are composed of varied micronutrients and a very viable, nutritionally efficient avenue for benefitting from the array of nutrients in fruits is through a beverage called a smoothie. Smoothies have been defined as a semi-liquid, mainly fruit-based product with a smooth consistency, or beverages that are produced from a blend of different fruits in appropriate proportions [3]. Smoothies, being a blend of a variety of fruits, therefore provide a good medium for obtaining the different micronutrients therein. However, since fruits are generally low in protein content, the resulting beverages (smoothies) will be deficient in this vital nutrient. A feasible means to address this is to supplement smoothies with other food materials, including vegetables with high protein content, such as M. oleifera leaves. Besides the need to encourage consumption of more fruit and vegetables, the concept of smoothies also 
resulted from the need for consumers to enrich their diets [3]. Therefore, the addition of Moringa leaf, reportedly contributing high protein content into smoothies may provide another avenue for obtaining additional benefits, nutritionally and otherwise, such as antioxidants. Therefore, the aim of this study was to evaluate the effects of M. oleifera leaves as a supplement to the nutritional composition, as well as the antioxidative properties of smoothies.

\section{Materials and Methods}

\subsection{Materials}

Fresh ripe fruits-pineapple (Ananas comosus), banana (Musa sapientum) and apple (Malus domestica) and vegetables (Moringa oleifera leaves) were bought from a local market in Akure, Ondo State, Nigeria. All the reagents used were of analytical grade and purchased from Sigma-Aldrich (St. Louis, MO, USA).

\subsection{Method}

The raw materials (fruit and vegetables) were sorted and thoroughly washed in clean water. Pineapples and bananas were peeled and the apples were cut open and the seeds removed. The cut fruits and vegetables were weighed and combined using the blending ratio shown in Table 1 on an electronic weighing balance. One hundred milliliters of clean water were added to each sample using the measuring cylinder and blended with an electric blender to obtain a semi-viscous liquid (smoothie).

Table 1. Blending ratio of fruit (g).

\begin{tabular}{cccccc}
\hline Samples & Pineapple (\%) & Banana (\%) & Apple (\%) & Moringa Leaf (\%) & Total (\%) \\
\hline CS & 45 & 40 & 15 & - & 100 \\
TA & 44.5 & 39.5 & 14.5 & 1.5 & 100 \\
TB & 44.0 & 39.0 & 14.0 & 3.0 & 100 \\
TC & 43.5 & 38.5 & 13.5 & 4.5 & 100 \\
\hline
\end{tabular}

\subsection{Analysis of the Smoothie}

The proximate composition (ash, fat, moisture content, protein and carbohydrates) and other analyses such as percentage brix, $\mathrm{pH}$, titratable acidity and specific gravity of the product were carried out using AOAC (2012).

\subsection{Determination of Vitamin C Content}

The vitamin $C$ content was determined using ascorbic acid as the reference compound. Two hundred milliliters of the extract were mixed with $300 \mathrm{~mL}$ of $13.3 \%$ of trichloroacetic acid (TCA) and $75 \mathrm{~mL}$ of 2,4-dinitrophenylhydrazine (DNPH.) The mixture was incubated at $37^{\circ} \mathrm{C}$ for $3 \mathrm{~h}$ and $500 \mathrm{~mL}$ of $\mathrm{H}_{2} \mathrm{SO}_{4}$ was added. The absorbance was read at $520 \mathrm{~nm}$ [4].

\subsection{Determination of Mineral Content}

The ash obtained after ashing was washed into a volumetric flask and made up to $100 \mathrm{~mL}$ with $2 \% \mathrm{HNO}_{3}$. It was analyzed using a Buck scientific VGP 210 Atomic Absorption spectrophotometer (Buck Scientific, Norwalk, USA).

\subsection{Determination of Total Flavonoid Content}

The total flavonoid content of the extract was determined using a colourimeter assay developed by Bao et al. [5] with some modifications. An aliquot $(0.2 \mathrm{~mL})$ of the extract was added to $0.3 \mathrm{~mL}$ of $5 \% \mathrm{NaNO}_{2}$ and after $5 \mathrm{~min}, 0.6 \mathrm{~mL}$ of $10 \% \mathrm{AlCl}_{3}$ was added followed by the addition of $2 \mathrm{~mL}$ of $1 \mathrm{M}$ 
$\mathrm{NaOH}$ after $6 \mathrm{~min}$ and $2.1 \mathrm{~mL}$ of distilled water. Absorbance was read at $510 \mathrm{~nm}$ against the reagent blank and flavonoid content was expressed as $\mathrm{mg}$ rutin equivalent.

\subsection{Determination of Total Phenolic Content}

The total phenolic content of the extract was determined by the method of Nabavi et al. [6] with some modifications. Two hundred microliters of the extract were mixed with $2.5 \mathrm{~mL}$ of $10 \%$ Folin Ciocalteau's reagent and $2 \mathrm{~mL}$ of $7.5 \%$ sodium carbonate. The reaction mixture was subsequently incubated at $45{ }^{\circ} \mathrm{C}$ for $40 \mathrm{~min}$ and the absorbance was measured at $700 \mathrm{~nm}$. Garlic acid was used as standard phenol.

\subsection{Determination of Radical Scavenging Ability (DPPH)}

The free radical scavenging ability of the extract against DPPH (1,1-diphenyl-2-picryhydrazyl) was carried out using the method of Nabavi et al. [6] with slight modification. One milliliter of the extract was mixed with $1 \mathrm{~mL}$ of the $0.4 \mathrm{mM}$ methanolic solution of the DPPH. The mixture was left in the dark for $30 \mathrm{~min}$ before measuring the absorbance at $517 \mathrm{~nm}$. The control consisted of methanol instead of the sample and the radical scavenging ability of the sample was calculated as:

$$
\% D P P H=\frac{A_{\text {control }}-A_{\text {sample }}}{A_{\text {control }}} \times 100
$$

\subsection{Determination of Ferric Reducing Antioxidant Power (FRAP)}

The reducing property of the extract was determined by taking $250 \mu \mathrm{L}$ of the sample into test tubes (with distilled water as a blank); $250 \mu \mathrm{L}$ of $0.02 \mathrm{M}$ of phosphate buffer ( $\mathrm{pH}$ 6.9) were added with $250 \mu \mathrm{L}$ of $1 \% \mathrm{~K}_{3}\left[\mathrm{Fe}(\mathrm{CN})_{6}\right]$. The mixture was incubated for $20 \mathrm{~min}$ at $50{ }^{\circ} \mathrm{C}$. Thereafter, $250 \mu \mathrm{L}$ of $10 \%$ TCA were added with $200 \mu \mathrm{L}$ of $0.1 \%$ freshly prepared $\mathrm{FeCl}_{3}$ and $1 \mathrm{~mL}$ of distilled water. The absorbance was read at $700 \mathrm{~nm}$.

\subsection{Sensory Evaluation}

The sensory evaluation of the smoothie samples was carried out by 20 trained panelists comprising students within the premises of the Federal University of Technology, Akure using a nine point hedonic scale where scores ranged from like extremely (1) to dislike extremely (9). Water was provided for each panelist for mouth rinsing after testing each product to avoid carry-over effect.

\subsection{Statistical Analysis}

Sample measurements were performed in triplicate and the data analyzed with SPSS version 17 (IBM, Armonk, NY, USA). The means were separated for significant differences $(p<0.05)$ using Duncan's Multiple Range test.

\section{Results and Discussion}

\subsection{Nutritional Composition of Smoothies Supplemented with M. oleifera Leaf}

The effect of level of $M$. oleifera leaf supplementation on proximate composition of smoothies made from the blends of pineapple, banana and apple is shown in Table 2. As expected, being beverages from fresh fruits, the smoothies showed high moisture content which significantly varied according to the level of Moringa leaf supplementation (49-79\%). The beverage may be able to serve as a thirst-quenching nonalcoholic beverage. The high moisture content may significantly affect the shelf-life of the beverage unless other preservative measures are taken. Total ash content is a reflection of the mineral composition of food samples. Addition of Moringa leaves significantly and progressively increased the total ash content of the smoothies. However, the significant increase in total ash did not result in substantial increase in the mineral elements analyzed (Table 3). M. oleifera leaf, which has 
been reported to possess high protein content [7], increased the total crude protein content of the smoothies by 157, 217 and 254\% for 1.5, 3.0 and 4.5 level of Moringa oleifera leaf supplementation, respectively. Efforts to improve nutritional composition of beverages, particularly with respect to protein content have been reported. One such measure is the addition of yoghurt and or milk to smoothies $[8,9]$. The protein content of the control sample is relatively comparable to protein content in the previous study, but those of the supplemented samples showed significantly higher values [10]. The fat content of the sample ranged from $0.72 \%$ to $1.86 \%$ while the ash content ranged between $1.01 \%$ and $9.71 \%$. The seemingly higher carbohydrate contents obtained for all the supplemented samples when compared to the control sample might be due to lower moisture contents in these samples rather than having more carbohydrate content than the control, which obviously has considerably higher moisture content. The range of moisture and carbohydrate contents obtained in the current study are within those reported in a previous similar study [11].

Table 2. Nutritional composition (\%) of smoothies supplemented with Moringa oleifera leaves.

\begin{tabular}{ccccc}
\hline Samples & CS & TA & TB & TC \\
\hline Moisture & $78.62 \mathrm{a} \pm 1.06$ & $68.05 \mathrm{~b} \pm 1.06$ & $53.31 \mathrm{c} \pm 1.06$ & $49.24 \mathrm{~d} \pm 1.06$ \\
Total ash & $1.01 \mathrm{~d} \pm 0.07$ & $5.62 \mathrm{c} \pm 0.07$ & $6.51 \mathrm{~b} \pm 0.07$ & $9.71 \mathrm{a} \pm 0.07$ \\
Crude fiber & $9.39 \mathrm{a} \pm 0.01$ & $6.29 \mathrm{~b} \pm 0.01$ & $5.14 \mathrm{da} \pm 0.01$ & $5.32 \mathrm{c} \pm 0.01$ \\
Crude fat & $1.86 \mathrm{a} \pm 0.01$ & $0.96 \mathrm{c} \pm 0.01$ & $0.72 \mathrm{~d} \pm 0.01$ & $1.59 \mathrm{~b} \pm 0.01$ \\
Crude protein & $5.47 \mathrm{~d} \pm 0.07$ & $14.05 \mathrm{c} \pm 0.07$ & $17.33 \mathrm{~b} \pm 0.07$ & $19.37 \mathrm{a} \pm 0.07$ \\
CHO & $3.65 \mathrm{~d} \pm 0.07$ & $5.03 \mathrm{c} \pm 0.07$ & $16.99 \mathrm{a} \pm 0.07$ & $14.77 \mathrm{~b} \pm 0.07$ \\
\hline
\end{tabular}

Data presented as mean \pm SD. Mean value in the same row with different superscript letters are significantly different $(p \leq 0.05)$. CS: $45 \%$ Pineapple, $40 \%$ Banana, $15 \%$ Apple; TA: $44.5 \%$ Pineapple, $39.5 \%$ Banana, $14.5 \%$ Apple, 1.5\% Moringa leaves; TB: 44\% Pineapple, 39\% Banana, 14\% Apple, 3\% Moringa leaves; TC: $43.5 \%$ Pineapple, 38.5\% Banana, $13.5 \%$ Apple, $4.5 \%$ Moringa leaves.

Table 3. Mineral composition (mg/L) of smoothies supplemented with Moringa leaves.

\begin{tabular}{ccccc}
\hline Samples & CS & TA & TB & TC \\
\hline Ca & $12.03 \pm 0.13 c$ & $11.21 \pm 0.13 \mathrm{~d}$ & $14.08 \pm 0.13 \mathrm{~b}$ & $15.53 \pm 0.13 \mathrm{a}$ \\
$\mathrm{K}$ & $22.60 \pm 0.10 \mathrm{~b}$ & $17.22 \pm 0.10 \mathrm{~d}$ & $20.54 \pm 0.10 \mathrm{c}$ & $25.38 \pm 0.10 \mathrm{a}$ \\
$\mathrm{Mg}$ & $3.05 \pm 0.14 \mathrm{a}$ & $2.58 \pm 0.14 \mathrm{~b}$ & $1.51 \pm 0.14 \mathrm{~d}$ & $1.96 \pm 0.14 \mathrm{c}$ \\
$\mathrm{Fe}$ & $0.008 \pm 0.05 \mathrm{c}$ & $0.009 \pm 0.05 \mathrm{c}$ & $0.018 \pm 0.05 \mathrm{a}$ & $0.014 \pm 0.05 \mathrm{~b}$ \\
Vit C & $3.3 \pm 0.02 \mathrm{~b}$ & $3.0 \pm 0.01 \mathrm{c}$ & $2.5 \pm 0.00 \mathrm{~d}$ & $10.8 \pm 0.04 \mathrm{a}$ \\
Vit E & $0.46 \pm 0.02 \mathrm{c}$ & $0.15 \pm 0.01 \mathrm{~d}$ & $0.63 \pm 0.02 \mathrm{~b}$ & $0.93 \pm 0.01 \mathrm{a}$ \\
\hline
\end{tabular}

Data presented as mean \pm SD. Mean value in the same row with different superscript letters are significantly different $(p \leq 0.05)$. CS: $45 \%$ Pineapple, $40 \%$ Banana, $15 \%$ Apple; TA: $44.5 \%$ Pineapple, $39.5 \%$ Banana, $14.5 \%$ Apple, 1.5\% Moringa leaves; TB: 44\% Pineapple, 39\% Banana, 14\% Apple, 3\% Moringa leaves; TC: $43.5 \%$ Pineapple, 38.5\% Banana, $13.5 \%$ Apple, $4.5 \%$ Moringa leaves.

\subsection{Mineral Elements and Vitamin Compositions of Smoothies Supplemented with M. Oleifera Leaves}

Part of the essential nutrients for proper growth and normal maintenance of the body are the micronutrients. While some are required at more concentration-macro minerals $\mathrm{Na}, \mathrm{K}, \mathrm{P}, \mathrm{Ca}$-others are only needed at very small quantity_trace elements, e.g., Fe, $\mathrm{Zn}$ and $\mathrm{Cu}$. These micronutrients play essential roles as cofactors for many metabolic processes in the body, hence their deficiency may result in significant nutritional deficiency diseases [12]. Table 3 shows the mineral element and vitamin composition of the smoothies. The content of $\mathrm{Ca}, \mathrm{K}, \mathrm{Mg}$ and $\mathrm{Fe}$ in the smoothies were determined. $\mathrm{K}$ had the highest value and was highest in sample TC $(25.38 \mathrm{mg} / \mathrm{L})$ than the remaining formulated samples $(22.60 \mathrm{mg} / \mathrm{L}, 20.54 \mathrm{mg} / \mathrm{L}$ and $17.22 \mathrm{mg} / \mathrm{L})$ respectively. The Ca content in the sample was also high in sample TC $(15.53 \mathrm{mg} / \mathrm{L})$ then followed by sample TA $(14.04 \mathrm{mg} / \mathrm{L}), \mathrm{CS}(12.03 \mathrm{mg} / \mathrm{L})$ and TB $(11.21 \mathrm{mg} / \mathrm{L})$. The vitamin contents results on the other hand showed that the smoothies blends were low in the vitamins especially vitamin $C$ when compared to $C a$ and $K$ contents. While vitamin $C$ ranged between 2.5 (TB) and 10.8 (TC), vitamin E content ranged between 0.15 (TA) and $0.93 \mathrm{mg} / 100 \mathrm{~g}$ (TC). Sample TC had the highest vitamin C content compared to others, which may be due to the presence 
of higher percentage of Moringa leaves in the sample. The values obtained in this study are lower than those reported for juices from other fruits [10]. The vitamin E content of the smoothies ranged from $0.15 \mathrm{mg} / 100 \mathrm{~g}$ to $0.93 \mathrm{mg} / 100 \mathrm{~g}$.

\subsection{The Phytochemical Composition of Smoothies Supplemented with Moringa Leaves}

The result of phytochemical compositions (total phenolic and total flavonoid contents) of smoothies made from pineapple, banana, apple and Moringa leaves is depicted in Figure 1A,B. Generally, the different smoothie's samples showed higher content of phenolic contents when compared to the flavonoid contents. This trend was also observed in a previous study [11]. The effects of the Moringa leaves on the phytochemical composition are reflected in the increase in total phenolic contents with increase in addition of Moringa leaves. However, the fact that a similar trend was not obtained for the flavonoid contents and considering the generally low values obtained for the total flavonoid content compared to the total phenolic content might suggest the presence of more phenolic compounds in the fruit and vegetables used. Polyphenolic compounds, including phenolic and flavonoid compounds, are parts of the bioactive components in food which possess health promoting properties such as anti-inflammatory, antidiabetic and antihypertensive properties, which have been the focus of many research studies [1,13-15].
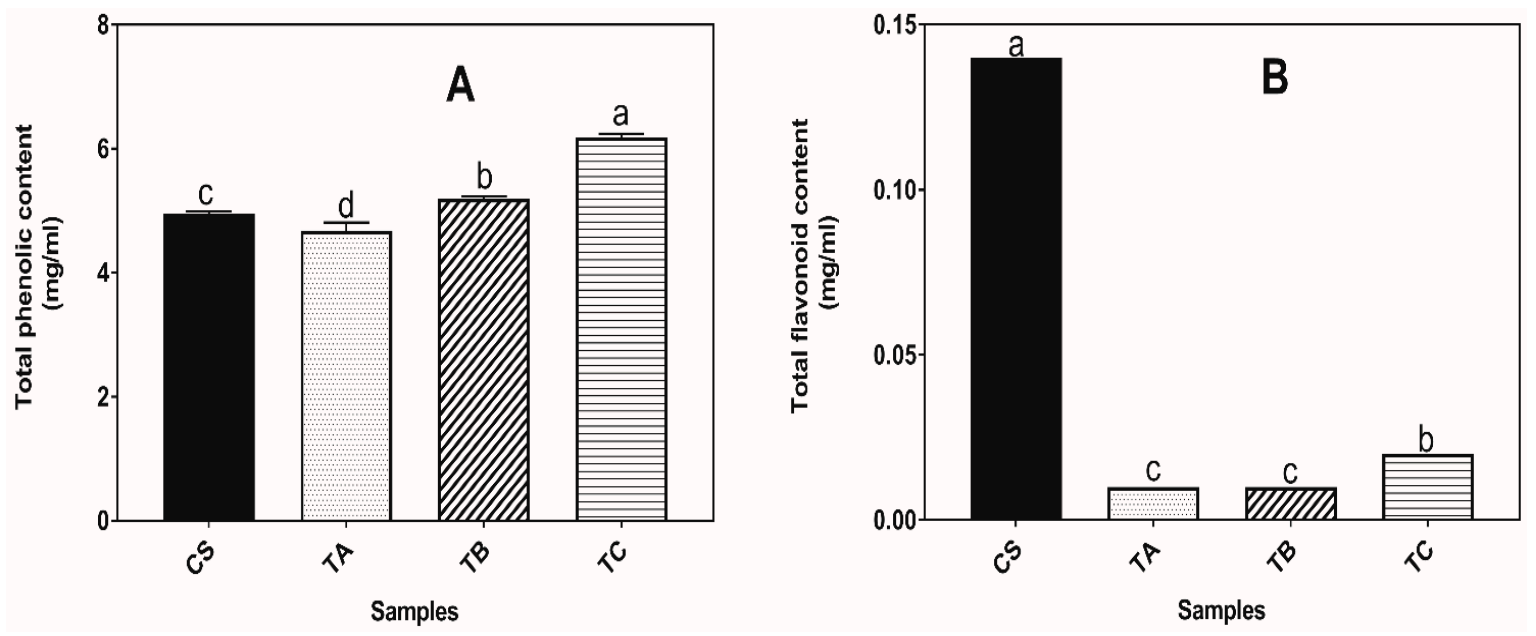

Figure 1. Percentage (mean \pm standard deviation, $n=3$ ) of (A) total phenolic and (B) total flavonoid contents of smoothies (TPC and TFC). Bars with different letters indicate values that are significantly different $(p<0.05)$. CS: 45\% Pineapple, 40\% Banana, 15\% Apple; TA: 44.5\% Pineapple, 39.5\% Banana, 14.5\% Apple, 1.5\% Moringa leaves; TB: 44\% Pineapple, 39\% Banana, 14\% Apple, 3\% Moringa leaves; TC: $43.5 \%$ Pineapple, $38.5 \%$ Banana, $13.5 \%$ Apple, $4.5 \%$ Moringa leaves.

\subsection{Antioxidant Properties of Smoothies Supplemented with Moringa Leaves}

Studies $[2,16]$ have reported the roles of antioxidants in preventing or ameliorating the effects of free radicals, which have been implicated in many diseases including diabetes, hypertension and cancer. Phenols and flavonoid compounds are bioactive components of foods with health-promoting properties, including antioxidative and anti-inflammatory properties [17]. Diets (foods, including beverages) which are basic to human survival therefore provide an economically feasible and sustainable alternative avenue to prevent or modulate some of the challenges posed by free radicals compared to drugs which are often expensive and can have side effects. The antioxidant capacity of the smoothies is shown in Figure 2A,B, with the free radical scavenging property (DPPH) ranging from $16 \%$ to $88.77 \%$. Both the free radical scavenging (DPPH) and ferric reducing abilities of the supplemented smoothies showed a similar trend, with an increase in their antioxidative potentials with increase in the level of Moringa leaf supplementation. That the two samples with higher Moringa leaf inclusion (TB and TC) were not favorably accepted by the consumers in the sensory ratings 
(Table 4) may confirm the age-old saying that sweeter foods are not as beneficial healthwise as less sweet foods. In the previous study [3], it was also observed that the health promoting potential of food was not directly correlated with the organoleptic properties, as the sample with the best antioxidative properties was less acceptable in consumer evaluation.
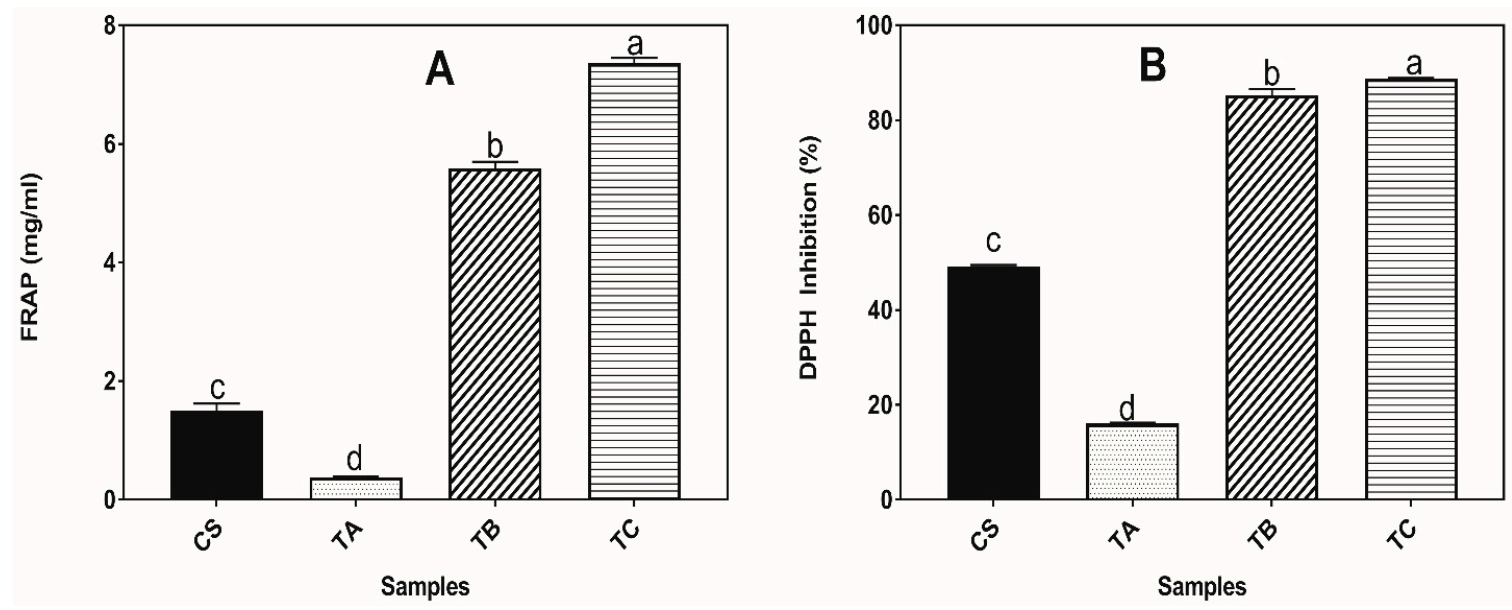

Figure 2. Percentage (mean \pm standard deviation, $n=3$ ) of antioxidant activities - (A) FRAP and (B) DPPH of the smoothies. Bars with different letters indicate values that are significantly different ( $p<0.05)$. CS: $45 \%$ Pineapple, 40\% Banana, 15\% Apple; TA: $44.5 \%$ Pineapple, 39.5\% Banana, $14.5 \%$ Apple, 1.5\% Moringa leaves; TB: 44\% Pineapple, 39\% Banana, 14\% Apple, 3\% Moringa leaves; TC: 43.5\% Pineapple, 38.5\% Banana, $13.5 \%$ Apple, $4.5 \%$ Moringa leaves.

Table 4. Sensory evaluation of the smoothies supplemented with Moringa leaves.

\begin{tabular}{ccccccc}
\hline Samples & Taste & Flavour & Mouth feel & Appearance & OverallAcceptability & Mean \\
\hline CS & $6.5 \pm 0.4 \mathrm{a}$ & $6.5 \pm 0.2 \mathrm{a}$ & $6.2 \pm 0.3 \mathrm{a}$ & $7.1 \pm 0.2 \mathrm{a}$ & $6.7 \pm 0.3 \mathrm{a}$ & $6.6 \pm 0.3 \mathrm{a}$ \\
TA & $5.7 \pm 0.3 \mathrm{~b}$ & $5.6 \pm 0.3 \mathrm{~b}$ & $5.7 \pm 0.4 \mathrm{~b}$ & $5.8 \pm 0.3 \mathrm{~b}$ & $5.6 \pm 0.3 \mathrm{~b}$ & $5.7 \pm 0.3 \mathrm{~b}$ \\
TB & $4.9 \pm 0.3 \mathrm{c}$ & $5.1 \pm 0.4 \mathrm{c}$ & $4.5 \pm 0.3 \mathrm{c}$ & $4.8 \pm 0.3 \mathrm{c}$ & $4.9 \pm 0.3 \mathrm{c}$ & $4.8 \pm 0.3 \mathrm{c}$ \\
TC & $4.2 \pm 0.3 \mathrm{~d}$ & $4.9 \pm 0.1 \mathrm{~d}$ & $4.2 \pm 0.3 \mathrm{~d}$ & $4.4 \pm 0.2 \mathrm{~d}$ & $4.6 \pm 0.3 \mathrm{~d}$ & $4.5 \pm 0.3 \mathrm{~d}$ \\
\hline
\end{tabular}

Values are means \pm standard deviation of triplicate readings. Means with different alphabetical superscript in the same column are significantly different at $(p<0.05)$. CS: $45 \%$ Pineapple, $40 \%$ Banana, $15 \%$ Apple; TA: $44.5 \%$ Pineapple, 39.5\% Banana, 14.5\% Apple, 1.5\% Moringa leaves; TB: 44\% Pineapple, 39\% Banana, 14\% Apple, 3\% Moringa leaves; TC: 43.5\% Pineapple, 38.5\% Banana, 13.5\% Apple, 4.5\% Moringa leaves.

\section{5. $p H, T T A$ and Percentage Brix of Smoothies Supplemented with Moringa Leaves}

The physicochemical ( $\mathrm{pH}$, TTA and brix) properties of smoothies are shown in Figure 3A-C. The $\mathrm{pH}$ values revealed that all the samples tended more towards neutral $\mathrm{pH}$ and ranged between 6.3 and 6.51, which shows no significant variation. These values are different from previous studies, where the $\mathrm{pH}$ of fruit juices were mainly acidic $[18,19]$. The gradual decrease observed in the brix content of the samples was expected, since brix measures the sugar content of foods. Obviously, Moringa leaves contain less sugar content compared to other fruit, hence the reduction in the brix values in Moringa supplemented smoothies. However, the current values are higher than those reported in the literature [19]. The total titratable acid of the smoothies ranged from 0.0084 to 0.0098 and decreased with increased level of Moringa leaves supplementation. The low TTA values for the supplemented sample did not have a corresponding effect in the taste rating by the consumer during sensory evaluation (Table 4). Though there are statistically significant differences in the TTA values, the range of the difference appeared too close to have any significant effect on the taste parameter. 

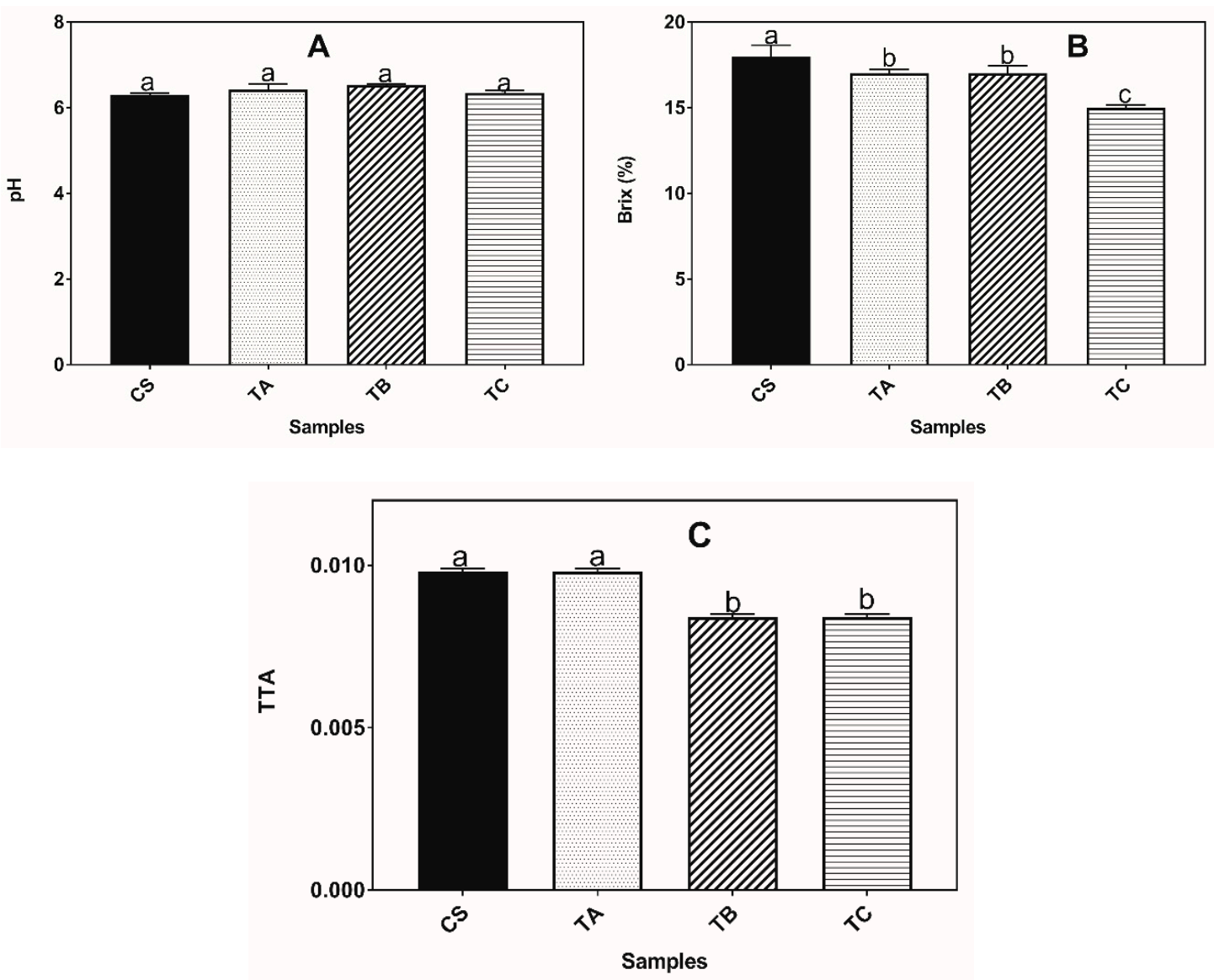

Figure 3. $\mathrm{pH}(\mathbf{A})$, Brix (B) and total titratable acid (TTA) (C) values (mean \pm standard deviation, $n=3$ ) of the smoothies. Bars with different letters indicate values that are significantly different $(p<0.05)$. CS: 45\% Pineapple, 40\% Banana, 15\% Apple; TA: 44.5\% Pineapple, 39.5\% Banana, $14.5 \%$ Apple, 1.5\% Moringa leaves; TB: 44\% Pineapple, 39\% Banana, 14\% Apple, 3\% Moringa leaves; TC: $43.5 \%$ Pineapple, 38.5\% Banana, 13.5\% Apple, 4.5\% Moringa leaves.

\subsection{Sensory Evaluation of the Smoothies Supplemented with Moringa Leaves}

Table 4 shows the result for the sensory characteristics of smoothie samples compared to the control sample. There was a significant $(p<0.05)$ difference between the control sample compared to other samples in terms of taste, flavour, mouth feel, appearance and overall acceptability. It is evident that smoothies with $0 \%$ Moringa leaves (control sample) had the highest score (7.1) while smoothies from sample TA, TB and TC were fairly rated by panelists with respect to appearance. Appearance (colour) that results from the presence of the different color-producing substances in the fruits and vegetable, such as anthocyanins, carotenoids and chlorophylls, is an important parameter used in judging the quality of foods, especially fruit/vegetable based beverages like smoothies $[1,20,21]$. In terms of appearance, a white/creamy appearance may be more appealing than greenish or other colour impacted by the addition of other raw materials/ingredients. This, however, might be due to the effect of the Moringa leaves, which imparted a greenish colour compared to the creamy appearance of the control sample. Similar trends were observed in the ratings of other parameters evaluated for the quality acceptability of the beverage. The apparently bitter taste of the leaf also significantly affected the taste, as reflected by the level of Moringa leaf supplementation. The low ratings obtained for taste in Moringa leaf supplemented samples may be expected since the brix results, which measures the sugar contents of the sample, was low compared to the control especially for sample TC, which was also rated lowest-indicating reduced sweetness. Influence of materials incorporated into smoothie production on its consumers' acceptability have also been reported [3]. The indirect relationship 
between antioxidant properties and consumer acceptability of smoothies, especially with the taste parameter, have been reported [22].

\section{Conclusions}

Supplementation of fruit (pineapple, banana and apple) smoothies with Moringa leaves led to the production of highly nutritious beverages. The protein content of the smoothies was significantly improved with the addition of Moringa leaves. The antioxidative properties of the beverages also significantly increased with the level of supplementation with Moringa leaves. Though inclusion of the leaves led to lower quality rating of the beverage-specifically in terms of taste, flavour, mouthfeel, appearance and overall acceptability-nevertheless, supplementation of smoothies with Moringa leaves may provide a better avenue to derive essential nutrients from the beverage, apart from the improved antioxidative properties.

Funding: This research received no external funding.

Conflicts of Interest: The author declares no conflict of interest.

\section{References}

1. Zinoviadou, K.G.; Galanakis, C.M.; Brn, M.; Grimi, N.; Boussetta, N.; Mota, M.J.; Saraiva, J.A.; Patras, A.; Tiwari, B.; Barba, F.J. Fruit juice sonication: Implications on food safety and physicochemical and nutritional properties. Food Res. Int. 2015, 77, 743-752. [CrossRef]

2. Varela-Santos, E.; Ochoa-Martinez, A.; Tabilo-Munizaga, G.; Reyes, J.E.; Pérez-Won, M.; Briones-Labarca, V.; Morales-Castro, J. Effect of high hydrostatic pressure (HHP) processing on physicochemical properties, bioactive compounds and shelf-life of pomegranate juice. Innov. Food Sci. Emerg. Technol. 2012, 13, 13-22. [CrossRef]

3. Teleszko, M.; Wojdyło, A. Bioactive compounds vs. organoleptic assessment of 'smoothies'-Type products prepared from selected fruit species. Int. J. Food Sci. Technol. 2014, 49, 98-106. [CrossRef]

4. Benderitter, M.; Maupoi, V.; Vergely, C.I.; Dalloz, F.; Briot, F.; Rochette, L. Studies by electron paramagnetic resonance of the importance of iron in the hydroxyl scavenging properties of ascorbic acid in plasma: Effects of iron chelators. Fundam. Clin. Pharcol. 1998, 12, 510-516. [CrossRef]

5. Bao, J.; Cai, Y.; Sun, M.; Wang, G.; Corke, H. Anthocyanins, Flavonols, and Free Radical Scavenging Activity of Chinese Bayberry (Myrica rubra) Extracts and Their Color Properties and Stability. J. Agric. Food Chem. 2005, 53, 2327-2332. [CrossRef] [PubMed]

6. Nabavi, S.M.; Ebrahinzadeh, M.A.; Nabavi, S.F.; Jafari, M. Free radical scavenging activity and antioxidant capacity of Eryngium caucasium trautv and Froripia subpinnata. Pharmacologyonline 2008, 25, 19-25.

7. Ogbe, O.; Affiku, J.P. Proximate Study, Mineral and Anti-Nutrient Composition of Moringa Oleifera Leaves Harvested From Lafia, Nigeria: Potential Benefits in Poultry Nutrition and Health. J. Microbiol. Biotechnol. Food Sci. 2011, 1, 296-308.

8. Keenan, D.F.; Brunton, N.P.; Gormley, T.R.; Butler, F.; Tiwari, B.K.; Patras, A. Effect of thermal and high hydrostatic pressure processing on antioxidant activity and colour of fruit smoothies. Innov. Food Sci. Emerg. Technol. 2010, 11, 551-556. [CrossRef]

9. El-Abasy, A.E.; Abou-Gharbia, H.A.; Mousa, H.M.; Youssef, M.M. Mixes of Carrot Juice and Some Fermented Dairy Products: Potentiality as Novel Functional Beverages. Food Nutr. Sci. 2012, 3, 233-239. [CrossRef]

10. Braide, W.; Oranusi, S.U.; Otali, C.C. Nutritional, antinutritional, minerals and vitamin compositions of fourteen brands of fruit juice sold in Onitsha main market. FS J. Res. Basic Appl. Sci. 2012, 1, 16-18.

11. Aderinola, T.A. Proceedings of the 4th Regional Food Science and Technology Summit (ReFoSTs), Akure, Nigeira, 6-7 June 2018; pp. 281-287.

12. Chukwuebuka, E. Moringa oleifera “The Mother's Best Friend". Int. J. Nutr. Food Sci. 2015, 4, 624-630. [CrossRef]

13. Žlabur, J.Š.; Dobri`cevic, N.; Pliestic, S.; Galic, A.; Bilic, D.P.; Voca, S. Antioxidant Potential of Fruit Juice with Added. Molecules 2017, 22, 2158. [CrossRef] [PubMed] 
14. Farasat, M.; Khavari-Nejad, R. Antioxidant Activity, Total Phenolics and Flavonoid Contents of some Edible Green Seaweeds from Northern Coasts of the Persian Gulf. Iran. J. Pharm. Res. 2014, 13, 163-170. [PubMed]

15. Oosthuizen, D.; Goosen, N.; Stander, M.; Ibrahim, A.; Pedavoah, M.-M.; Usman, G.; Aderinola, T. Solvent Extraction of Polyphenolics from the Indigenous African Fruit Ximenia caffra and Characterization by LC-HRMS. Antioxidants 2018, 7, 103. [CrossRef]

16. Aderinola, T.A.; Fagbemi, T.N.; Enujiugha, V.N.; Alashi, A.M.; Aluko, R.E. Amino acid composition and antioxidant properties of Moringa oleifera seed protein isolate and enzymatic hydrolysates. Heliyon 2018, 4, e00877. [CrossRef] [PubMed]

17. Sun-Waterhouse, D.; Nair, S.; Wibisono, R.; Wadhwa, S.S.; Massarotto, C.; Hedderley, D.I.; Zhou, J.; Jaeger, S.R.; Corrigan, V. Insights into Smoothies with High Levels of Fibre and Polyphenols: Factors Influencing Chemical, Rheological and Sensory Properties. Int. J. Nutr. Food Eng. 2010, 4, 378-387.

18. Sukeri, J.F.T.P.K.S. The effects of fruit smoothies on enamel erosion. Eur. Arch. Paediatr. Dent. 2014, 15, 175-181.

19. Li, R.; Wang, Y.; Wang, S.; Liao, X. A Comparative Study of Changes in Microbiological Quality and Physicochemical Properties of N 2 -Infused and N 2-Degassed Banana Smoothies After High Pressure Processing. Food Bioprocess Technol. 2015, 8, 333-342. [CrossRef]

20. Barba, F.J.; Esteve, M.J.; Frígola, A. High pressure treatment effect on physico-chemical and nutritional properties of fluid foods during storage. Compr. Rev. Food Sci. Food Saf. 2012, 11, 307-322. [CrossRef]

21. Wang, S.; Lin, T.; Man, G.; Li, H.; Zhao, L.; Wu, J.; Liao, X. Effects of Anti-browning Combinations of Ascorbic Acid, Citric Acid, Nitrogen and Carbon Dioxide on the Quality of Banana Smoothies. Food Bioprocess Technol. 2014, 7, 161-173. [CrossRef]

22. Nowicka, P.; Wojdy, A.; Samoticha, J. Sensory attributes and changes of physicochemical properties during storage of smoothies prepared from selected fruit. LWT Food Sci. Technol. 2016, 71, 102-109. [CrossRef]

(C) 2018 by the author. Licensee MDPI, Basel, Switzerland. This article is an open access article distributed under the terms and conditions of the Creative Commons Attribution (CC BY) license (http:/ / creativecommons.org/licenses/by/4.0/). 